\title{
Del furioso cañoneo al eco de Bolívar: guerra, ciudad y sonoridad en Lima, 1819-1826
}

\author{
SUSY SÁNCHEZ \\ Universidad de Notre Dame \\ ssanche7@gmail.com
}

\section{RESUMEN}

Este articulo presenta la sonoridad conmemorativa y disruptiva experimentada en la ciudad de Lima durante la guerra de la independencia, haciendo énfasis en los sonidos desplegados por campanas y cañones. A pesar de que, en Lima, ni patriotas ni realistas se llegaron a enfrentar en una batalla a campo abierto, la guerra marcó de modo contundente el ambiente sonoro en la ciudad. La sonoridad disruptiva emitida por campanas y cañones en el transcurso de la guerra superó ampliamente en intensidad y duración a la sonoridad conmemorativa auspiciada por el gobierno independiente, e incluso tuvo el poder de modificarla dramáticamente.

Palabras clave: campanas, salvas de artillería, conmemoraciones, independencia, bloqueo al Callao, Bolivar

\section{ABSTRACT}

This article examines the soundscape, both commemorative and disruptive, experienced in the city of Lima during the War of Independence, focusing on the sounds produced by church bells and cannons. Even though, in Lima, patriots and royalists never fought a pitched battle, the war resoundingly marked the city's aural environment. Disruptive noise emitted by church bells and cannons 
during the war greatly exceeded in intensity and duration the commemorative sounds sponsored by the independent government, and even had the power to change it dramatically.

Keywords: church bells, artillery salvos, commemorations, Independence, the Callao blockade, Bolivar

L viajero inglés Robert Proctor narró la conmoción sonora sentida en
la ciudad de Lima a consecuencia del motín ocurrido en las fortalezas del Callao el 5 de febrero de 1824. Proctor refirió que el mencionado día:

como a las ocho de la mañana, nos alarmaron gritos horribles en las calles, y, precipitándonos a las ventanas, vimos que la gente corría a sus casas, e inmediatamente cerraba las puertas. Gran concurso de gente había en el mercado cercano y proferían los gritos más afligentes, buscando cobijarse en cualquier parte. Me figuré al principio que la alarma provenía de un terremoto; pero un momento de reflexión me convenció de que ésa no podía ser la causa, pues la gente en tal caso se precipitaría de las casas a las calles en vez de refugiarse adentro: además, sonaban violentamente las campanas tocando somaten y jinetes galopaban por las calles en todas las direcciones [...]. A mediodía oímos claramente los cañones grandes del Callao e inmediatamente corrieron rumores sobre la causa de los cańonazos. ${ }^{1}$

La experiencia vivida por Proctor nos aproxima a la dimensión sensorial de la guerra, en una ciudad cuyos habitantes debían distinguir entre los ruidos de los movimientos telúricos y los producidos por el conflicto bélico. Entre los sonidos mencionados por Proctor, llaman la atención las referencias que hace a la violencia sonora de las campanas y la zozobra causada por el inusual estruendo de los cañones. Cabe destacar que el testimonio de Proctor no representa un hecho anecdótico o aislado. Las memorias de viajeros y militares que vivieron la guerra de la independencia en la ciudad de Lima demuestran cómo la población limeña durante este periodo estuvo expuesta a una amplia gama de sonidos disruptivos. El intenso cańoneo, el impetuoso repique de las campanas y

1 Proctor 1971-1976: 318; el énfasis es mío. 
el paso de la caballería, ruido que incluso fue comparado con el sentido durante los temblores, fueron los que más destacaron.

Asimismo, la experiencia auditiva de Proctor nos proporciona un sugerente indicio que confirma la particularidad de las ciudades capitales en el estudio de los sonidos producidos por la población y los espacios que ocupan, en especial en periodos de guerra. La concentración del poder político, económico y social convierte a las ciudades en escenarios sonoros armónicos o caóticos en constante circulación, movimiento y transformación. ${ }^{2}$ Como lo ha señalado Véronique Hébrard, la ciudad «como espacio físico y simbólico» constituye «un instrumento privilegiado para analizar lo que ocurre en un país en guerra civil». ${ }^{3}$ En efecto, en el caso de Lima durante la guerra de la independencia, los ejércitos patriota y realista no se enfrentaron en una batalla a campo abierto. Sin embargo, desde 1819, la guerra marcó de modo contundente el ambiente sonoro en la ciudad, con el inicio del bloqueo de lord Cochrane al Callao hasta 1826, cuando las fuerzas realistas capitularon en las fortalezas del Callao. Pero, al mismo tiempo, desde la proclamación de la independencia en julio de 1821, con el objetivo de legitimar su proyecto político, el régimen independiente utilizó la sonoridad conmemorativa expresada a través de la música de las bandas militares, los repiques de las campanas, las salvas de artillería y los ecos festivos. Como desarrollaremos a continuación, la sonoridad disruptiva de campanas y cañones superó ampliamente en intensidad y duración a la sonoridad conmemorativa emitida por estos objetos sónicos dispuesta por el gobierno independiente, e incluso tuvo el poder perturbador de modificarla dramáticamente.

\section{CIUDAD, GUERRA Y AMBIENTE SONORO}

Este artículo se suscribe a la tendencia historiográfica que estudia la dimensión sensorial de la vida urbana. Siguiendo la propuesta teórica del historiador francés Alain Corbin, este artículo identifica la guerra de la independencia en Lima como productora cultural y social de sounds-

2 Boutin 2015: 8, 55; y DeFazio 2011.

3 Hébrard 2003a y 2003b. 
capes. Corbin identificó la esencia binaria que los caracteriza, ya que los paisajes sonoros constituyen un ambiente físico al mismo tiempo que una construcción cultural, es decir, mundos percibidos. ${ }^{4}$ Durante la última década, otros investigadores dedicados a la historia cultural de la ciudad han expandido la perspectiva de Corbin, al analizar el rol simbólico y espacial de los sonidos en la cotidiana construcción de los espacios urbanos. En especial, se ha reconocido el impacto de la guerra en la producción de extraordinarios ambientes sonoros, al poner de manifiesto la dimensión política y simbólica de los silencios, los toques de campana y los sonidos marciales. El historiador norteamericano Mark Smith, por ejemplo, al analizar la sonoridad de la guerra civil norteamericana, demostró el poder transformador de los sonidos militares de disparos y cañonazos en la vida pública de la ciudad de Charleston en Carolina del Sur. Las batallas se transformaron en soundscapes únicos para los soldados, ya que estos tuvieron que entender los códigos del silencio de las armas, mientras que los pobladores de las ciudades desarrollaron sistemas de advertencia basados en los toques de las campanas. ${ }^{5}$ Carolyn Birdsall en su estudio sobre el ambiente sonoro de la ciudad de Dusseldorf durante el régimen nazi en Alemania propone la distinción entre sonoridad conmemorativa oficialmente sancionada y la sonoridad disruptiva producida por la guerra. Con respecto a la primera categoría, Birdsall amplía la tesis original de Benedict Anderson que identifica la nación como una comunidad imaginada y demuestra el poder de los rituales sonoros en la conformación de una "comunidad imaginada de oyentes» en los ámbitos urbanos. En lo concerniente a la sonoridad disruptiva, la autora enfatiza el rol transcendental de la guerra en la proliferación de sonidos en la ciudad y los cambios que esta provoca en la vida urbana, y concluye que los sonidos disruptivos de los bombardeos experimentados en la ciudad durante la Segunda Guerra Mundial superaron ampliamente el espectro sonoro regulado desplegado durante las conmemoraciones del régimen nazi. ${ }^{6}$

4 Corbin 1998: 95. Un excelente balance historiográfico que valora la apuesta de Corbin sobre las experiencias sensoriales se ofrece en Pinch y Bijsterveld 2013: 8.

5 Smith 2001: 208-214; 2014.

6 Birdsall 2012. 
En el caso latinoamericano, al relacionar guerra y sonoridad en tiempos de la independencia, destacan los casos mexicano, chileno y peruano. Con respecto a las celebraciones de la independencia en México, Carmen Nava ha demostrado como estas ofrecen un escenario singular para el estudio de la campana como símbolo sonoro fundacional del imaginario patriótico tanto en el ámbito urbano como rural. ${ }^{7} \mathrm{El}$ historiador chileno Jaime Valenzuela, al investigar el poder persuasivo y legitimador de la sonoridad castrense en Chile, ha establecido que, a partir de las reformas militares borbónicas durante la segunda mitad del siglo XVIII, las descargas de cañones adquirieron un mayor protagonismo sonoro debido al poder disuasivo y espectacularidad que los caracteriza. La crisis imperial de la Monarquía española y las guerras insurgentes consolidaron la hegemonía previamente gestada de los sonidos marciales en el espacio público en Chile. ${ }^{8}$ Para el caso de la ciudad de Lima, el historiador argentino Pablo Ortemberg, se ha referido al ritual sonoro del 28 de julio como componente de la «negociación simbólica» que implicó la proclamación de la independencia del Perú, así como el reglamento sobre el uso de las campanas, decretado por Bernardo de Monteagudo en 1822, el cual buscaba, según el autor, "tener incidencia en la cultura popular y religiosa» pues repetía el edicto de 1795 que ya restringía el uso de las campanas. ${ }^{9}$

Los historiadores referidos ofrecen sólidos trabajos de larga duración sobre la dimensión simbólica, urbana y política de la transición de los

7 Nava y Fernández Tejedo 2010.

8 Valenzuela Márquez 2010a. Para un estudio más amplio sobre la sonoridad castrense en Chile, véase Valenzuela Márquez 2010b: 135-173. Previamente el mismo autor ya había abordado el rol simbólico, político y urbano de las campanas (Valenzuela Márquez 2001: 365, 367, 369, 370 y 374).

9 Ortemberg 2014: 235. Sobre el Protectorado, véanse Ortemberg 2006 y 2009. Este autor ha presentado de modo elocuente el rol estratégico de los rituales en la construcción de «experiencias sensoriales de control político y social». No obstante, enfatiza en la visualización de los emblemas y en la escenificación del ritual, ya que, como el mismo lo señala, ambos eran considerados «dispositivos pedagógicos» cruciales de las fiestas del poder, más que el poder sonoro de las campanas y las salvas de artillería (Ortemberg 2012). Para la escritura de este artículo hemos utilizado la versión digital de su libro, por lo cual quiero expresar mi agradecimiento al autor. 
borbones al régimen independiente; no obstante, el ritual sonoro aparece jugando un rol complementario. Por lo tanto, si bien se ha reconocido el papel protagónico de la ciudad durante las guerras de la independencia, una historia sensorial de la misma está todavía por escribirse. El estudio de la dimensión sonora de la guerra contribuiría a enriquecer la historia social y medioambiental del proceso independentista.

En ese sentido, este artículo presenta la sonoridad conmemorativa y disruptiva experimentada en la ciudad de Lima durante la guerra de la independencia. La sonoridad conmemorativa demuestra cómo el régimen independentista se esforzó en construir «una comunidad imaginada de oyentes» al transformar las ceremonias conmemorativas en momentos acústicos claves en la tarea de comunicar el proyecto político. Al regular los repiques de las campanas y las salvas de artillería a ser emitidos, propagados y escuchados durante las celebraciones, el régimen buscaba la legitimación sensorial entre la población. Es decir, el proyecto regenerador del régimen identificado con la Patria debía constituirse en una experiencia sensorial audible. Sin embargo, la sonoridad disruptiva emitida por campanas y cańones en el trascurso de la guerra superó ampliamente en intensidad y duración a la sonoridad conmemorativa de repiques y salvas de artillería. La guerra impuso la dinámica sonora de la ciudad, demostrando en diversas coyunturas la impotencia política, militar y simbólica del proyecto patriota.

Siguiendo la metodología sugerida por Birdsall en el análisis de la sonoridad experimentada en la Alemania nazi, inicialmente hicimos la distinción entre la sonoridad conmemorativa o regulada diferenciándola de la sonoridad disruptiva inherente al conflicto bélico. Una evaluación cualitativa de las mismas demostró el amplio espectro sonoro que caracterizó esta época. No obstante, para la escritura de este artículo, optamos por enfatizar los sonidos emitidos por campanas y cańones, ya que en ambos casos reflejan la tensión auditiva vivida en esos años de guerra, al cumplir un rol conmemorativo pero también disruptivo. Con respecto a la sonoridad conmemorativa catalogamos las disposiciones oficiales concernientes al horario y la intensidad de los repiques de las campanas, así como el número de disparos de cañón por salva de saludo militar, 
en el periodo comprendido desde julio de 1821, cuando se proclamó la independencia del Perú, hasta febrero de 1826, cuando se celebró la capitulación de la fortaleza del Callao. Para ello, hemos consultado la Colección de Leyes de Juan Oviedo, la Gaceta de Gobierno Independiente, los bandos del gobierno, la documentación del cabildo limeño en diferentes colecciones, la documentación española, los epistolarios y la obra gubernativa tanto de la época de San Martín como la de Bolívar publicadas en la Colección Documental de la Independencia del Perú. Para la identificación de la sonoridad disruptiva que caracterizó la evacuación de la ciudad por los ejércitos patriota y realista, así como los bloqueos patriotas al puerto y a las fortalezas del Callao, nos han sido de mucha utilidad las memorias de los militares, los periódicos de la época y las relaciones de los viajeros. En este aspecto, quisiéramos destacar las memorias de los militares, puesto que demuestran una gran acuciosidad auditiva tanto a nivel cualitativo como cuantitativo al momento de registrar los sonidos propios del fragor del combate o los sonidos celebratorios de las victorias militares, ya sean propios o del enemigo. ${ }^{10}$

Para demostrar el peso determinante de la guerra en la conformación del ambiente sonoro en Lima desde 1819 hasta 1826, este artículo está divido en tres partes, cada una de las cuales explica una coyuntura diferente. Hemos optado por una secuencia cronológica en lugar de una estructura temática, ya que esta permite incluir la dinámica política de la guerra y contextualizar históricamente la producción regulada y disruptiva de los sonidos. La primera parte, titulada «Del furioso cañoneo en el Callao a la cautela sonora castrense de la Patria», presenta la sonoridad disruptiva producida por los ataques de la escuadra chilena liderada por lord Cochrane a la fuerza naval realista emplazada en la bahía del Callao y a las fortalezas del Real Felipe en 1819 y 1820. Posteriormente, nos referimos a la apropiación plebeya de las campanas ocurrida en la ciudad ante la evacuación del ejército realista. Enseguida presentamos la sonoridad conmemorativa dispuesta para la proclamación de la independencia en julio del mismo año, la cual identificamos

${ }^{10}$ Sobre la capacidad auditiva de los militares, véanse Kutzler 2014 y Wolmar 2014. 
como cautelosa, ya que se dio un despliegue limitado de los sonidos marciales en comparación con las juras reales de los reyes borbónicos y las celebraciones de la toma de Lima en Chile. En la segunda parte, que hemos denominado "El estruendo sonoro de la República ficticia», se analiza la crítica coyuntura que experimentó el régimen de la Patria en la capital peruana desde junio de 1823 hasta febrero de 1824. En junio de 1823, ante el avance militar realista, el gobierno independiente se retiró hacia Trujillo. Pocas semanas después, los realistas abandonaron la ciudad y el ejército patriota la recuperó. Sin embargo, como los patriotas perdieron el control de la fortaleza del Callao en febrero de 1824, el ejército realista volvió a controlar la capital peruana, pero en esta ocasión por el lapso de varios meses. Este acápite presenta el protagonismo de la sonoridad conmemorativa en recrear una República ficticia. Este régimen, al construir un ciclo de intensidad sonora castrense, el cual tuvo como punto culminante los homenajes al Libertador Simón Bolívar en septiembre de 1823, se negaba a morir. Sin embargo, como lo demostraría el poder disruptivo de las campanas y los cańones, la guerra tuvo un impacto definitivo en el ambiente sonoro limeño. Por último, la tercera parte, titulada «El fin de la guerra: El bloqueo patriota en el Callao y el eco de Bolívar», presenta la hegemonía sonora de la figura heroica de Libertador en la capital peruana, debido a los triunfos militares. El eco festivo protagonizado por la voz de la multitud al vitorear al héroe libertador respondía en gran parte al objetivo de atenuar la cacofonía de la sonoridad bélica, producida por el intenso bloqueo patriota a las fortalezas del Callao en el transcurso de 1825, el cual finalmente logró liquidar la resistencia realista dirigida por Rodil. Con la capitulación de este a inicios de 1826 se silenciaba finalmente el ruido estremecedor de los cañones, los que inicialmente habían sido escuchados en Lima en 1819 debido al bloqueo de lord Cochrane.

\section{DEL FURIOSO CAÑONEO EN EL CALLAO A LA CAUTELA SONORA DE LA PATRIA}

El primer ataque al Callao, ocurrido el 28 de febrero de 1819 por parte de la escuadra chilena dirigida por lord Cochrane, produjo una potente 
conmoción sonora tanto en el puerto como en la ciudad. Según los atacantes, la bahía del Callao se convirtió en un infierno de explosiones por el lapso de dos a dos horas y media. Un testimonio sonoro patriota exalta la figura de lord Cochrane al señalar que el marino británico, dirigiendo la fragata Almiranta O’Higgins, ordenó el fuego de 300 piezas de cañón. ${ }^{11}$ Por otra parte, los testimonios realistas enfatizan la contundente respuesta militar al fuego activo de los insurgentes por parte de las 200 piezas de artillería ubicadas en la fortaleza del Real Felipe y los disparos realizados por los buques y las lanchas cañoneras estacionadas en la bahía. Pero más aún señalan el estremecimiento que experimentaron las edificaciones en la ciudad de Lima a consecuencia del prolongado e intenso combate. El propio virrey Pezuela escuchó, desde el Palacio, el «horrible fuego de cañón» procedente del Callao a partir de las tres de la tarde, el cual, según él, duró un lapso de cuatro horas. ${ }^{12} \mathrm{Si}$ bien los testimonios mencionados difieren en señalar la duración del combate, ambas versiones destacan la intensidad del sonido bélico. Además, este estruendo confirma lo precisado por Timothy Anna, quien explica que el primer bloqueo marítimo chileno sobre el Callao anunció la gran vulnerabilidad militar y comercial de la ciudad de Lima. ${ }^{13}$ En los años anteriores, las campanas de Lima no habían cesado de repicar celebrando las victorias que el ejército realista obtenía en Chile. Pero, a partir de febrero de 1819, con la presencia de la escuadra bloqueadora procedente desde el sur, «el azote de la guerra se presentaba a las puertas de la ciudad». ${ }^{14}$ Aunque todavía de forma esporádica, la guerra se convertía en una realidad audible, al alterar ostensiblemente la cultura auditiva de la población.

En íntima relación con el bloqueo al Callao, el viajero William Bennet Stevenson señaló en sus memorias que, a media noche del 3 de marzo de 1819, «se oyó un ruido de disparos» en la calle Malambo, ubicada en

${ }^{11}$ Espejo 1971-1976: 407; Alvarez Jonte 1971-1976: 441, 443; y Cochrane 1863: 9-13, 136. Véase, además, Archivo Nacional 1946-1985, XII: 152, 162, 297.

12 Pezuela 1947: 411; García Camba 1916, I: 407- 408.

13 Anna 2003: 190, 210.

${ }^{14}$ Stevenson 1971-1976: 251. 
el barrio de San Lázaro. Por lo cual se formó una aglomeración de gente en la mencionada calle. Para los patriotas, esos ruidos indicaban el lugar de reunión, mientras que para los realistas anunciaban el desembarco patriota. Stevenson muy bien anotó que «las gentes de los dos bandos preguntaban con ansiedad qué significaba el ruido de las detonaciones, y se retiraron sin tener una explicación satisfactoria». ${ }^{15}$ Con el transcurrir de los meses la sonoridad disruptiva del cañón sería una realidad más constante. A fines de septiembre y principios de octubre de 1819, Cochrane llevó a cabo una segunda ola de ataques al puerto. El mismo virrey Pezuela señaló que, para el día 10 de octubre, Cochrane había ejecutado siete ataques nocturnos que habían dejado oír un "furioso cañoneo» en el Callao. ${ }^{16}$ Las situaciones referidas demuestran la sensibilidad sonora de la población limeña y de las autoridades del gobierno ante la sucesión de sonidos disruptivos. La violencia acústica del bloqueo sentido durante la noche provocaba un ambiente de expectativas, pero también de miedo e incertidumbre.

Sin embargo, no fue sino hasta fines de 1820, después del desembarco de la expedición libertadora, que Cochrane impuso un bloqueo más contundente. En un ataque nocturno, el 5 de noviembre de 1820, los insurgentes capturaron la fragata nombrada La Esmeralda, de cuarenta y cuatro cańones. Una vez más «los castillos y las baterías de la costa empezaron a vomitar fuego" contra los botes armados patriotas, pero fue en vano. El fuerte cañoneo se escuchó desde las 12 hasta las 4 de la mañana. Se contabilizó que las baterías del Callao lanzaron 82 cañonazos solo hasta la una y cuarto. ${ }^{17}$ Para el virrey Pezuela, la captura de la nave de guerra española más importante del Pacífico fue la «circunstancia más adversa de la guerra». ${ }^{18}$ En contraste, el 6 y el 9 de noviembre, los buques sitiadores celebraron con salvas de 21 cañonazos la captura de la Esmeralda y saludaron a lord Cochrane. El empleo de salvas de regocijo no era una novedad en la bahía del Callao. El 18 de septiembre, se habían

\footnotetext{
${ }^{15}$ Stevenson 1971-1976: 249-251.

${ }^{16}$ Pezuela 1947: 532, 534; y Archivo Nacional 1946-1985, XIII: 186.

${ }^{17}$ Paroissien 1971-1976: 560; y Archivo Nacional 1946-1985, XIV: 270.

${ }^{18}$ Barra 1971-1976: 220.
} 
disparado salvas celebrando el aniversario de Chile y, el 4 de noviembre, al tener noticias de la proclamación de la independencia de Guayaquil llevada a cabo el 9 de octubre. ${ }^{19}$ Estas salvas de júbilo, al antagonizar con el caos, la confusión y el ruido pavoroso del combate, cumplieron el rol de comunicadores acústicos de la superioridad marítima y militar de las fuerzas navales bloqueadoras. A su vez, se constituían en un código sonoro que notificaba a población de la ciudad que las armas de la Patria iban ganando la guerra y que pronto Lima sería liberada del poder realista.

Desde la pérdida de La Esmeralda en noviembre de 1820 hasta junio de 1821, Lima experimentó un bloqueo marítimo total y un cerco por tierra, confirmándose así la fragilidad militar de la ciudad. El virrey La Serna y su ejército evacuaron la capital peruana los primeros días de julio de 1821. En el ámbito sonoro, este vacío de poder sin precedente se puso de manifiesto, primero, por el bullicio de los que dejaban la ciudad por temor a las armas de la Patria y, posteriormente, por el silencio de los que habían optado por permanecer en ella. El viajero británico Basil Hall narró el estado de «gran agitación», "gritería y confusión» protagonizada por hombres, mujeres y niños quienes marcharon de manera masiva hacia la fortaleza del Callao o hacia los conventos de la ciudad buscando protección. En contraste, el mismo 6 de julio, pocas horas después de la partida del virrey, Lima se transformó en una "ciudad muerta» donde «reinó la más profunda tranquilidad durante la noche», sentenció Hall. ${ }^{20}$ El silencio se debía al temor a la plebe, y estaría en relación con lo que Gustavo Montoya identificó como el «fantasma de la revolución»; es decir, el temor de la población blanca a un levantamiento en masa de la población esclava. ${ }^{21}$

Este temor no era completamente infundado. La plebe rompió el silencio de la ausencia militar realista y trastornó el horizonte acústico de la ciudad al apropiarse de las campanas. Los días 9 y 10 de julio se registraron desórdenes populares. El general realista Andrés García

${ }^{19}$ Espejo 1971-1976: 412, 415, 418, 420; Paroissien 1971-1976: 541, 562; y Torrente 1971-1976: 160-162.

${ }^{20}$ Hall 1971-1976: 226, 228.

${ }^{21}$ Montoya 2002: 100-113. 
Camba anotó en su memoria que «a la vista de los invasores alguna plebe, la mayor parte compuesta por gente de origen africano [...] hizo repicar las campanas». ${ }^{22}$ En tiempos normales, los discordantes tañidos de las campanas de las 54 iglesias de la ciudad producían «la combinación más bárbara imaginable de ruidos» que al ser tan aturdidores imposibilitaban «escuchar nada atentamente durante los repiques». ${ }^{23}$ Las medidas represoras ordenadas por el designado gobernador político militar de la ciudad, Pedro José Zarate y Navia, marqués de Montemira, demuestran la sonoridad disruptiva de la apropiación plebeya de las campanas en la situación mencionada. Esta autoridad de la ciudad emitió un bando prohibiendo la circulación y la aglomeración de personas a partir de las siete de la noche. Pero, en especial, dispuso castigar a quienes forzaran las puertas de los campanarios o los que repicaran las campanas sin autorización del gobierno, al considerarlos como perturbadores del sosiego público. ${ }^{24} \mathrm{La}$ apropiación subversiva de las campanas ayuda a entender por qué el ejército liderado por San Martín se comprometió ante el Cabildo limeño a proteger la ciudad garantizando la tranquilidad pública y el mantenimiento del orden. ${ }^{25}$ En un momento de transición, la apropiación plebeya de las campanas trastornaba la función de uno de los objetos más simbólicos del poder eclesiástico destinado a regular los ritmos temporales de la vida urbana. ${ }^{26}$

Las campanas, al jugar el rol de íconos de la colectividad urbana, comunicaron e informaron a la población sobre la presencia del ejército patriota. El viajero Basill Hall señaló que la entrada de las tropas patriotas los días 9 y 10 de julio hizo posible que la ciudad volviera a «su acostumbrado ruido [...]; las calles se llenaron de gente [...] y las campanas tañeron de nuevo». ${ }^{27}$ Francisco Javier Mariátegui refirió que los repiques de campanas saludaron el ingreso de la caballería patriota.

${ }^{22}$ Corbacho 1911: 184; y García Camba 1916, I: 538.

23 Proctor 1971-1976: 264; y Delano, 1971-1976: 20.

${ }^{24}$ Odriozola 1863-1877, IV: 297-298.

${ }^{25}$ Herrera 1862:35. Sobre el rol del ejército como garante del orden, véase Gálvez Peña 2012.

26 Sobre este punto, véase Dávalos 2011.

27 Hall 1971-1976: 230; y Corbacho 1911: 184. 
Por ello, no sorprende que se escucharan repiques generales de campanas, primero, por la declaración de la independencia y, luego, por el ingreso del vicealmirante lord Cochrane, quien había dirigido el ensordecedor bloqueo al puerto del Callao. Este protagonismo sonoro de las campanas, en contraste con el silencio de las armas militares, cumplía el objetivo político de contrarrestar la propaganda realista que había señalado que el ejército patriota saquearía la ciudad. ${ }^{28} \mathrm{~A}$ pesar de que una fuerza militar ocupaba la ciudad, esta necesitaba la seguridad emocional de los repiques de las campanas y no el estremecedor poder sónico de los cañones. Las armas de la Patria no podían hacer uso de la contundencia sonora de la artillería, ya que esta podría haber lanzado el mensaje equívoco de la realización de la temida batalla por Lima entre patriotas y realistas. ${ }^{29}$

La proclamación de la independencia del Perú resignificó el rol conmemorativo y simbólico de las campanas. El Cabildo de la ciudad de Lima ordenó la ejecución de repiques generales durante los días 27, 28 y 29 de julio. Un testigo militar señaló «que el viernes 27 por la noche empezó el repique general, que entusiasmó a las gentes que de puro gozo no podían contenerse en sus casas, y al momento se llenaron las calles y la plaza Mayor ". ${ }^{30} \mathrm{El}$ sábado 28 de julio, en la plaza Mayor, las famosas expresiones de San Martín, Viva la Patria, Viva la independencia, "fueron recogidas y repetidas por la multitud que llenaba la plaza y las calles adyacentes, mientras repicaban todas las campanas y se hacían salvas de artillería entre aclamaciones tales como nunca se había oído en Lima». ${ }^{31}$ Otros testimonios de la proclamación también señalan la excepcionalidad sonora del eco festivo que acompañó a las vivas de San Martín, ya que

${ }^{28}$ Mariátegui 1971-1976: 69-70; y Denegri 1971-1976b, II: 489.

${ }^{29}$ Gamio Palacio 1971: 14. Aquí se reproduce el pedido de los miembros del Cabildo limeño al virrey Pezuela de diciembre de 1820, cuando la entidad edilicia propuso una "capitulación honorífica» tendiente a evitar una batalla en Lima entre patriotas y realistas, la cual conllevaría a la ruina de la ciudad. Se hizo evidente el miedo al incendio de la urbe.

${ }^{30}$ Denegri 1971-1976b, II: 490.

${ }^{31}$ Hall 1971-1976: 242. 
en ese momento «se multiplicaron los repiques y las salvas de artillería ensordecían con sus estampidos». ${ }^{32}$

El énfasis en la excepcionalidad sonora de la proclamación de la independencia en el escenario urbano limeño respondía al deseo de formar una "comunidad imaginada de oyentes» identificada con el régimen de la Patria. Las campanas y las salvas de artillería jugaron el rol de movilizadores acústicos al propagar una intensa carga emocional que celebraba la conversión de Lima de contrarrevolucionaria en patriota. A través del ritual sonoro se buscaba modificar la experiencia sensorial de la población. Los bien entrenados oídos de la población limeña, acostumbrados a escuchar el eco festivo celebrando la causa del rey y ofendiendo la causa patriota, ahora atendían el nacimiento político del régimen de la Patria en el Perú. ${ }^{33}$

Sin embargo, en comparación con la sonoridad castrense de carácter conmemorativo en tiempos del rey, la proclamación de la independencia reveló la «amputación sonora» producida por la guerra. El 28 de julio las salvas de artillería acompañaron la proclamación de San Martín. El día 29 de julio, durante la misa de acción de gracias, se escucharon las salvas de artillería en la plaza Mayor y en el parque de Santa Catalina. ${ }^{34}$ Pero, un hecho que llama la atención es que el bando de proclamación del 28 de julio no especificó el horario de ejecución y el número de las salvas de artillería. ${ }^{35}$ Este es un detalle de suma importancia en consideración con la sonoridad castrense que caracterizó a las ceremonias de los reyes borbónicos en la ciudad de Lima. El 20 de agosto de 1789, 21 tiros de cañón lanzados al mediodía anunciaron las honras fúnebres para Carlos III. Seguidamente, las baterías de artillería en el Callao dispararon un tiro cada cuarto de hora hasta caer la noche, al igual que los repiques dobles

32 Gamio Palacio 1971: 64. Con respecto al eco festivo de la proclamación una descripción oficial señalaba: «resonaron en toda la plaza, entre el estrepito de los cañones y el repique de todas las campanas de la ciudad» (Odriozola 1863-1877, IV: 270).

${ }^{33}$ La ofensa auditiva por parte de los patriotas en Lima es indicada en la obra de Manuel Santiago Concha (1971-1976: 28).

${ }^{34}$ Denegri 1971-1976b, II: 491; y Hall 1971-1976: 242.

35 «Bando para la Proclamación de la Independencia» 1821: 17-18. 
de campanas. ${ }^{36}$ En la jura real de Carlos IV en 1790, se oyeron salvas al amanecer; y, en el transcurrir del día, se escucharon la repetición de repiques generales y fuegos artificiales, a las doce, a las dos e incluso a la hora de las oraciones. ${ }^{37}$ Las salvas de artillería en el Callao se entienden ya que, desde tiempos de los virreyes Superunda y Amat en el siglo XVIII, la fortaleza del Callao o Real Felipe se había convertido en el baluarte defensivo de la ciudad de Lima. En cambio, en 1821, el nuevo régimen identificado con el de la Patria no pudo ordenar salvas de artillería en el Callao, debido al control realista de la fortaleza del Real Felipe.

Inmediatamente después de su ingreso a la ciudad de Lima, el ejército patriota inició el asedio por mar y tierra a la fortaleza del Real Felipe, baluarte realista de resistencia militar. A partir del 13 de julio, se hizo frecuente el escuchar los tiroteos sostenidos entre la guarnición militar realista del Callao y las guerrillas patriotas, así como el fuego nocturno lanzado por las embarcaciones bloqueadoras hacia la fortaleza, las que continuaban hasta el amanecer. ${ }^{38}$ La proclamación de la independencia del Perú, al no ser el resultado de una batalla victoriosa sobre el enemigo realista que conllevara a la capitulación de este, no pudo recibir el estruendo conmemorativo de los cañones en toda su amplitud, intensidad y duración. Los cañones todavía cumplían un rol preponderantemente disruptivo.

La sonoridad conmemorativa del régimen patriota cambió en septiembre de 1821, a consecuencia de la rendición realista de las fortalezas del Callao. Los ministros Bernardo de Monteagudo e Hipólito Unanue decretaron la celebración de la entrega de la fortaleza el 21 de septiembre con una salva de artillería en el momento en el cual se tremolara el estandarte de la «INDEPENDENCIA». En septiembre de 1821, asimismo, el gobierno dispuso el repique de las campanas de todas las iglesias de la ciudad, levantándose oficialmente la prohibición de tocar las campanas sin autorización previa dada en julio con la finalidad de

\footnotetext{
${ }^{36}$ Reales exequias 1789: 129.

37 Terralla y Landa 1790.

${ }^{38}$ García Camba 1916, I: 538, 539, 541; y Comisión Nacional del Centenario 19101911: 450 .
} 
contener los desórdenes de la plebe. ${ }^{39}$ A pesar de ser una victoria militar, la captura de la fortaleza del Callao, resignificó el simbolismo sónico de las campanas, ya que, de modo inequívoco, el gobierno apelaba a la eficacia sonora de las mismas para comunicar a la población que la ciudad y el puerto estaban finalmente bajo control patriota.

La restringida sonoridad conmemorativa castrense desplegada durante el momento fundacional del régimen de la Patria en la capital peruana es incluso más evidente en comparación con el ritual sonoro auspiciado por el gobierno chileno celebrando la toma de Lima. El 20 de agosto de 1820, la expedición libertadora dirigida por el general San Martín, compuesta por 4700 hombres, zarpó del puerto chileno de Valparaíso después de recibir la resonante despedida de las salvas de los cañones de los buques de guerra. ${ }^{40}$ En noviembre de 1820, un repique general de campanas en Santiago celebró el desembarco de las fuerzas independentistas en el territorio peruano. ${ }^{41}$ Por lo tanto, cuando el 13 de agosto de 1821 llegó la noticia de liberación de Lima a Santiago, salvas de artillería y repiques de campanas celebraron el evento. Los cohetes no cesaron hasta el amanecer del día 14 y la salva de la artillería concluyó al anochecer. Ese mismo día se escuchó una salva de 100 cañonazos saludando el retorno de las banderas patriotas que habían sido capturadas por los realistas en la batalla de Rancagua ocurrida el 2 de octubre de 1814. El ejército libertador las había recuperado en la iglesia de Santo Domingo en Lima. ${ }^{42}$ Cabe recalcar que, en ninguna oportunidad, durante los años de la guerra de la independencia, se dispuso o se escuchó una salva de tal intensidad al unísono en la capital peruana en celebración alguna. Este contundente patrón sonoro desplegado en Chile no nos debe sorprender, ya que ejemplifica la «fundación castrense de la República» en ese país, tal como lo ha especificado Jaime Valenzuela. ${ }^{43} \mathrm{El}$ júbilo sonoro en la capital

\footnotetext{
${ }^{39}$ Oviedo 1861-1872, IV: 351.

${ }^{40}$ Stevenson 1971-1976: 266.

${ }^{41}$ Archivo Nacional 1946-1985, XIV: 139.

${ }^{42} \mathrm{Ib}, \mathrm{XV}: 255-256$.

${ }^{43}$ En Chile se había proclamado la independencia después de las victoriosas batallas obtenidas por las fuerzas patriotas en Chacabuco y Maipú. Estos triunfos militares por
} 
chilena se entiende porque la toma de Lima sellaba la «emancipación política» de Chile. San Martín había proclamado la independencia del Perú, pero, como la sonoridad conmemorativa lo demuestra, esta fue más festejada en Santiago que en Lima.

\section{EL ESTRUENDO SONORO DE LA REPÚBLICA FICTICIA}

En junio de 1823, la ciudad de Lima experimentaría el retorno de las fuerzas realistas. El presidente José de la Riva-Agüero anunció una defensa vigorosa de la ciudad; sin embargo, el gobierno concluyó imprudente arriesgar el destino del régimen de la Patria en una batalla. Por ello ordenó la retirada hacia la fortaleza del Callao, pero las autoridades optaron por marchar rumbo a Trujillo y establecerse allí de modo provisional. Como ya había acontecido en julio de 1821, se produjo una bulliciosa migración de la población, buscando refugio en el Callao o en los conventos de la ciudad, después de lo cual las calles estuvieron desiertas. ${ }^{44}$ El 18 de junio, el ejército realista ocupó Lima sin resistencia, puesto que el ejército patriota se había ya retirado a las fortalezas del Callao. A su ingreso a la ciudad, el Cabildo «desplegó la exaltación de su gozo en el repique de campanas, vivas y aclamaciones generales». ${ }^{45}$ Una vez más, Lima se libraba de convertirse en teatro de guerra a campo abierto, y las campanas anunciaban el suceso. Las fuerzas realistas bajo el mando de Canterac y Rodil permanecieron en la capital hasta el 16 de julio.

El 18 de julio de 1823, los toques de las campanas anunciaron el retorno de las fuerzas patriotas a la capital peruana. El general de brigada Tomás Guido, al asumir el gobierno de la ciudad, decretó el repique de campanas desde las siete hasta las ocho de la noche durante los días 19, 20 y 21 del mes en curso. ${ }^{46}$ Esta disposición expresaba que la guerra imponía cambios.

los cuales San Martín era considerado héroe libertador, eran celebrados con grandes desfiles militares donde destacaba el protagonismo sonoro de las salvas de artillería. Al respecto, véase Valenzuela Márquez 2010b: 171-173.

${ }^{44}$ Fundación Eugenio Mendoza 1967, I: 206; Thomson 1971-1976: 35-36; Oviedo 1861-1872, I: 186; y Proctor 1971-1976: 206.

${ }^{45}$ Comisión Nacional del Centenario 1910-1911, X: 470.

${ }^{46}$ Oviedo 1861-1872, IV: 357; y Fundación Eugenio Mendoza 1967, I: 214. 
Se ordenaba un repique de campanas durante tres días conforme a lo decretado para las festividades cívicas, como fue el caso de la proclamación de la independencia. Sin embargo, cabe destacar que la duración diaria de los repiques en esta oportunidad superó al repique general de campanas dispuesta para la víspera de la sesión inaugural del Congreso Constituyente dada el 22 de septiembre de 1822, cuando todas las iglesias de la ciudad hicieron un repique de media hora a partir de las siete de la noche. ${ }^{47}$ Indudablemente, el retorno del régimen de la Patria a la capital peruana era un motivo para celebrar. El tono afectivo de estos objetos sónicos servía para marcar un tiempo nuevo, eliminando la sonoridad disruptiva oída en Lima a raíz de las refriegas entre patriotas y realistas. Durante la ocupación realista de la ciudad se escucharon «cañoneos en los fuertes», y la población estuvo "frecuentemente alarmada de noche por escaramuzas furiosas fuera de las murallas» y los constantes tiroteos de más o menos duración. ${ }^{48}$ Por lo tanto, en 1823 , como ya había ocurrido en julio de 1821, el simbolismo marcial de los cañones no resultaba conveniente al gobierno independentista, ya que estos hubieran confundido a la población, la cual equivocadamente habría asumido el retorno del enemigo realista a la capital o un enfrentamiento bélico entre ambos ejércitos. En este caso, la repetición de los repiques reinscribía a la ciudad de Lima en el tiempo de la Patria nuevamente.

Recuperada la normalidad, la sonoridad conmemorativa propalada durante el mes de agosto de 1823 buscó recrear el ambiente sonoro de una Patria victoriosa, que revertía la ocupación realista. En este contexto, se escuchó la contundencia y espectacularidad de la artillería a la par de los repiques de las campanas. Para celebrar la reinstalación del Congreso, los días 6, 7, y 8 de agosto, se dispuso repiques generales con una duración de un cuarto de hora cada uno a partir de las siete de la noche. En esta oportunidad, sí se ordenó el estruendo de las salvas de 21 cañonazos durante tres días, los que se llevarían a cabo en el parque de artillería, en las fortalezas del Callao, tanto a las seis de la mañana

${ }^{47}$ Oviedo 1861-1872, I: 172; y Ortemberg 2014: 286.

48 Proctor 1971-1976: 217; y García Camba 1916, II: 83-84. 
como a las seis de la tarde. El 12 de agosto, un cañonazo en la plaza de la Independencia (plaza Mayor) y el repique general de campanas comunicaron al pueblo limeño la llegada de los diputados desterrados por el destituido presidente Riva-Agüero. Para el reconocimiento de José Bernardo de Tagle como nuevo presidente, se dispusieron repiques generales durante los días 17, 18 y 19 de agosto de 1823, y salvas de 21 cañonazos durante el Te Deum y una hora después en el Callao. Los días 25 y 27 de agosto, la ciudad celebró triunfos militares patriotas ocurridos en el sur, con salvas de 22 cañonazos en el parque de artillería al ponerse el sol y repique de campanas e iluminación general a las 7 de la noche. ${ }^{49}$ Todo este despliegue sonoro buscaba impresionar a la comunidad imaginada de oyentes en Lima y sensibilizar a la audiencia sobre la viabilidad del proyecto independentista.

La construcción de este ciclo de intensidad sonora confirma la precisión de María Soledad Barbón, quien establece que la «maquinaria ritual» se hace más "apremiante en momentos de crisis, ruptura o transición». ${ }^{50}$ En efecto, a nivel militar, en ese momento, Lima era sede de una República ficticia, ya que el gobierno peruano estaba constreñido a la ciudad de Lima, porque la sierra central y sur estaban bajo el poder de los realistas, a lo que agregaba la anarquía política protagonizada por Riva-Agüero en el norte y Torre Tagle en Lima. Asimismo, esta intensa dinámica sonora castrense se constituía en la antesala de las mayores demostraciones de júbilo que la capital peruana tributaría a la figura heroica de Simón Bolívar.

La sonoridad marcial destinada a festejar el arribo de Bolívar en septiembre de 1823 transformó este evento en un hito sonoro a nivel simbólico y urbano. El presidente Tagle ordenó el repique general de campanas y una salva de 22 cañonazos en el parque de artillería al momento de la llegada del Libertador al puerto del Callao, acto que se repetiría al ponerse el sol. Asimismo, continuando con la tradición, un

49 Oviedo 1861-1872, I: 187; «Don José Bernardo Tagle» 1823; y Fundación Eugenio Mendoza 1967, I: 231, 256.

${ }^{50}$ Barbón 2012: 172. 
repique general a las 7 de la noche estaría acompañado de la iluminación de las casas de la ciudad. ${ }^{51}$ Bolívar llegó a Lima el 1 de septiembre de 1823. Pocos días después, el 10 de septiembre, el Congreso Constituyente le otorgó «la suprema autoridad militar en todo el territorio de la República» con la finalidad de conseguir «la salvación del país». ${ }^{52}$ Los cuatro días posteriores, desde el 11 hasta el 14 de septiembre, Bolívar fue homenajeado por 10 salvas de 22 cańonazos cada una, ejecutados en la plaza Mayor, en el parque de artillería, en el Callao y por los buques de la armada. ${ }^{53}$ Ningún evento o personalidad política hasta ese momento había recibido tan contundente homenaje militar, y superaba ampliamente la sonoridad conmemorativa castrense de la proclamación de la independencia.

En septiembre de 1823, Lima recibía al líder guerrero indiscutible de la independencia en Sudamérica. El despliegue sonoro hacia Bolívar se entiende porque, según el Congreso peruano, la presencia de este en el Perú se constituía en «un golpe mortal a los opresores del Perú» ya que él concluiría la "guerra en el suelo de los Incas». La presencia de Bolívar servía para autenticar la vigencia del proyecto independentista, un tiempo nuevo, el cual debía asumirse como un proyecto regenerador y convertirse en una experiencia sensorial tangible. Como bien lo ha señalado Hébrard, el poder paternal y autoritario encarnado por Bolívar se constituían en la mejor garantía de "éxito y esplendor de la Patria». ${ }^{54}$

A pesar de la excepcional contundencia de las salvas en honor a la llegada de Bolívar, la República ficticia asentada en Lima no podía prescindir de las campanas con la finalidad de afianzar su legitimidad sensorial en la población. En noviembre de 1823, Lima asistió a la jura de la Constitución de la República Peruana que sancionaba la independencia del Perú de la monarquía española. Con tal motivo, se dispuso el saludo militar de las salvas de artillería a las autoridades del gobierno en el parque de artillería y en las fortalezas del Callao. Esta dinámica

${ }^{51}$ Fundación Eugenio Mendoza 1967, I: 263.

${ }^{52}$ Ib.: 267.

53 Ib.: 271.

${ }^{54}$ Hébrard 2012: 450, 451, 452. 
sonora se repetiría luego de la publicación en sí de la Carta. El ceremonial contemplaba un mayor protagonismo de las campanas e iglesias, al ordenarse repiques generales saludando a la comitiva del gobierno, pero también repiques particulares llevados a cabo en las iglesias ubicadas en cada una de las siguientes plazas: Mayor, de la Merced, San Pedro y de la Constitución, tanto al ingreso de la comitiva como al término de la publicación de la Carta. Siguiendo la tradición, el repique general de campanas precedería a una iluminación en todas las calles de la capital. ${ }^{55}$ En este caso, se hizo explícito el poder legitimador de la sonoridad de las campanas en rendir honores a las autoridades del gobierno. Si bien las salvas de artillería siguieron articulando la complementariedad sonora entre Lima y el Callao, los repiques particulares reforzaron la dimensión simbólica y política de las campanas y las iglesias, ya que estas identificaban los espacios y los tiempos de los momentos claves de la proclamación de la primera constitución de la República. Las campanas otorgaban espectacularidad y sacralidad a una Constitución que en la práctica resultaba más ficción que realidad, pues debido a la preponderancia militar realista, nació para morir inmediatamente porque no tuvo vigencia. ${ }^{56}$ A pesar de esta circunstancia, la publicación de la Constitución se convertía en una necesidad política, ya que se debían reafirmar los resortes simbólicos del régimen.

El precario régimen, para proclamar su sobrevivencia política, necesitaba del respaldo tradicional, religioso y cotidiano de las campanas, símbolo inequívoco del pasado colonial. Esto quedó confirmado cuando, para saludar el retorno de Bolívar a la ciudad en enero de 1824, se ordenó el repique general de campanas. Este debía iniciarse justo en el momento en el cual el Libertador estuviese próximo a la Portada de Guía y debía cesar cuando este ingresara a su habitación en Magdalena. ${ }^{57} \mathrm{El}$ protagonismo sónico de las campanas auspiciadas para saludar a militares de la talla de Bolívar confirma el énfasis de Corbin sobre el rol de estas como

${ }^{55}$ Oviedo 1861-1872, I: 48; y Fundación Eugenio Mendoza 1967, I: 342.

${ }^{56}$ Aljovín de Losada 2001.

${ }^{57}$ Denegri 1971-1976a, I: 139. 
objetos simbólicos únicos en la construcción de identidades individuales y colectivas. ${ }^{58}$ Este aspecto también ha sido destacado por otros autores, quienes enfatizan la trascendencia de las campanas como objetos emisores de poderos signos sonoros capaces de conformar comunidades de escucha y, a la vez, de delimitar áreas geográficas u horizontes acústicos. El poder sónico de la campana es capaz de convertir eventos cotidianos en patrones temporales de la comunidad. ${ }^{59}$ En el caso del recibimiento a Bolívar, se hacía patente el afán de delimitar una comunidad de escucha subordinada al Libertador. Su ingreso a la ciudad debía llegar a oídos de toda la población de la ciudad.

Sin embargo, la dinámica de la guerra desmanteló el objetivo de solemnizar la presencia sonora de campanas y cañones e impuso la presencia disruptiva de los mismos. La noche del 5 de febrero de 1824, los sargentos Dámaso Moyano y otro apellidado Oliva, pertenecientes a la Compañía de Granaderos del Río de la Plata, entregaron la fortaleza del Callao a los realistas. Simbólicamente, una salva general acompañó la colocación de la bandera española. Este hecho produjo una conmoción sonora en la ciudad tal como lo describió el viajero Robert Proctor, quien señaló que, en la mañana del 5 de febrero, en la ciudad de Lima «sonaban violentamente las campanas» y al mediodía "oímos claramente los cañones grandes del Callao». Por ello se dieron medidas de precaución para la seguridad pública. Proctor indicó que «al sonido de la campana de la catedral se ordenó que todos los hombres se reuniesen en la plaza, preparados si fuera necesario, pelear por su vida y sus bienes», ya que se esperaba el ataque de los amotinados. Proctor indicó también que el 20 de febrero por la tarde «se oyó en el Callao cañoneo más nutrido que de costumbre» como resultado del fuego cruzado entre el navío La Prueba y los motineros del Callao. Estos últimos dispararon entre doscientos y trescientos cañonazos, aunque con poco efecto. ${ }^{60}$ El testimonio de Proctor reitera el rol disruptivo de campanas y cañones impuesto por la guerra, tanto a nivel temporal como espacial.

\footnotetext{
${ }^{58}$ Corbin 1998:158.

${ }^{59}$ Smith 1999; y Burgess y Wathey 2000: 1-46.

${ }^{60}$ Proctor 1971-1976: 318, 320, 321.
} 
La complementariedad política, militar y sonora entre la urbe y el puerto se había resquebrajado una vez más. Si durante las ceremonias auspiciadas por el gobierno las salvas de artillería acompañaban el Te Deum dado en la catedral, ahora en una coyuntura crítica, las campanas de la catedral servían de epicentro de la seguridad urbana, en respuesta al desorden y el caos propalado por el cańoneo en el Callao.

En febrero de 1824, la República ficticia quedó finalmente liquidada. La pérdida de las fortalezas del Callao, considerado «el golpe más terrible que podía recibir la causa de la independencia», ${ }^{61}$ causó la evacuación del ejército patriota y el ingreso de las tropas realistas a la ciudad. El 27 de febrero, las tropas patriotas conducidas por Necochea se retiraron de Lima. Sin un ejército que garantice el orden social, la población de la ciudad vivió una noche horrible de detonaciones a consecuencia del saqueo desatado por los amotinados de la fortaleza del Callao. Las notas de música marcial ejecutadas por miembros del ejército español simbolizaron el fin de la anarquía y la confusión. El 29 de febrero de 1824, los realistas tomaron posesión de la ciudad. Si bien la población ocupó las calles, estas estuvieron dominadas por un «un silencio mortal, sin manifestarse bienvenida ni disgusto». Los realistas pasaron directamente hacia el Callao donde una gran salva de artillería anunció el arribo de las tropas a la fortaleza del Real Felipe. ${ }^{62}$ Una vez más, Lima se había librado de una confrontación abierta entre patriotas y realistas, como ya había acontecido en 1821 y 1823 . No obstante, la guerra estaba todavía lejos de terminar y, por lo tanto, la población continúo oyendo la sonoridad disruptiva de los cañones.

\section{EL FIN DE LA GUERRA: EL BLOQUEO PATRIOTA EN EL CALLAO Y EL ECO DE BOLÍVAR}

El asedio patriota a las fortalezas del Callao significó una intensa sonoridad disruptiva de los cañones nunca antes oída. La guerra por la independencia había quedado finiquitada con el triunfo patriota en la

61 García Camba 1916, II: 151.

62 Proctor 1971-1976: 328. 
batalla de Ayacucho. La Capitulación de Ayacucho expresamente señaló la entrega de la fortaleza del Callao al ejército libertador. No obstante, el jefe militar realista Rodil, quien la gobernaba, no la reconoció y optó por una tenaz resistencia de la plaza. El general Bartolomé Salom, por órdenes de Bolívar, dirigió las fuerzas sitiadoras patriotas durante el ańo 1825 hasta el 23 de enero de 1826, cuando Rodil capituló. Salom formó una línea de baterías de cañones en distintos puntos estratégicos que circundaban la fortaleza, ubicados en Bellavista, el camino al Callao, la Huaca Barbosa y la Mar Brava. De acuerdo con la sensibilidad auditiva realista, desde estos parapetos «se hacía un fuego horrible i no interrumpido». ${ }^{63}$ Solo para tener una idea de la intensidad del enfrentamiento, según el jefe realista de la plaza durante el sitio se dispararon 74.014 tiros de cañón, obus y mortero. ${ }^{64}$ La acuciosa contabilidad llevada a cabo por la división sitiadora del Callao da cuenta de que, solo durante los días 2, 3 y 4 de abril de 1825, la artillería realista lanzó 1292 tiros de cañón. ${ }^{65}$ Este número de tiros de cañón en el periodo señalado superaba ampliamente las salvas de artillería dedicadas a Bolívar durante la semana de homenajes que recibió a su arribo al Perú en septiembre de 1823, el cual había constituido un hito de la sonoridad conmemorativa de los cañones sin precedentes.

Los patriotas sacralizaron el estruendo producido por la artillería de sus armas, mientras se propendía a una demonización del cañoneo realista. Por ejemplo, una descripción decía:

Al salir la aurora del día 2 del presente (abril) el señor general comandante de la división sitiadora hizo romper el fuego a nuestra batería titulada Bolívar. Este acto se verificó al son de la música y enarbolando el Pabellón de la República [...]. El enemigo hizo un horroroso fuego sobre ambas direcciones, pudiéndose contar en el resto del día tan solamente de los castillos 315 tiros de cañón, 21 de mortero y 15 de obus. ${ }^{66}$

\footnotetext{
63 Torrente 1829-1830, III: 527.

${ }^{64}$ A lo que se agregaba 34.700 de metralla, «y sufrió de los enemigos 20.317 balas de grueso calibre, 307 bombas e incalculable número de metralla, por ser el proyectil que más abundaban, y del cual hacían mayor uso, al paso que adelantaban sus obras sobre la expresada plaza» (García Camba 1916, II: 384).

${ }^{65}$ Fundación Eugenio Mendoza 1967, II: 423-424.

${ }^{66} \mathrm{Ib}$.
} 
El afán por antagonizar los sonidos de la Patria y los del enemigo se constituía en una estrategia de consolidación emocional de la comunidad imaginada de oyentes. Los cañones de la Patria, al estar umbilicalmente unidos al héroe libertador, se convertían en objetos sónicos sublimes, cuya potencia sonora formaba parte de un cuidadoso programa patriótico musical. En oposición, al identificar los tiros de cañón lanzados por el enemigo como «horroroso fuego", transformaba a estos en una disonancia perturbadora para el régimen de la Patria, por lo cual debía ser extirpada, ya que emanaban desorden, destrucción y agresión. Por ello, cuando las fuerzas sitiadoras capturaron la fortaleza en enero de 1826, lanzaron salvas de artillería en el torreón de la Patria como señal de victoria. La sonoridad disruptiva de la artillería, al transformarse en conmemorativa, silenciaba la cacofonía bélica que había caracterizado el bloqueo.

El intenso sitio en el Callao transmutó la sonoridad conmemorativa dedicada a Bolívar al catapultar la voz de la multitud en el marcador primario del orden sonoro centrado en la figura de este. El 10 de febrero de 1825, al celebrarse el aniversario de la dictadura, «una salva de artillería anunció al pueblo la restauración de la libertad». Ese mismo día, en el homenaje tributado por el Congreso a Bolívar, las voces de la muchedumbre agitaban «incesantes vivas que retumbaban por todas partes», al mismo tiempo que los repiques de campanas anunciaban el paso del Libertador por las calles de la ciudad. Ya en el Congreso, la multitud imbuida de frenesí patriótico prorrumpió «gritos excesivos de Viva BOLIVAR, viva el LIBERTADOR del Perú». ${ }^{67}$ Una composición poética titulada Oda: Lima Libre y Pacífica publicada en ese año decía: «BOLIVAR VIVA, en todos los lugares /El eco retumbando. Se repiten las vivas a millones. /Oye la voz BOLIVAR: se sorprende con tan solemne súbito consuelo». ${ }^{68} \mathrm{~A}$ través de la demostración vocal de la multitud se buscaba superar la cacofonía bélica producida durante el intenso bloqueo al Callao. La resonancia del eco tenía la capacidad de organizar a la

${ }^{67}$ Ib.: 281-282.

${ }^{68}$ J. M. V. 1825: 8. 
población y consolidar una comunidad imaginada de oyentes centrada en el héroe libertador. ${ }^{69}$

La capitulación de las fuerzas realistas a inicios de 1826 ameritaría una entrada triunfal de Bolívar a Lima. El 8 de febrero de 1826 el estruendo de la salva realizada por el bergantín Chimborazo anunciaba la proximidad de Bolívar a la ciudad. Poco después, un repique general de campanas confirmaba a la población limeña el arribo del Padre de la Patria. ${ }^{70} \mathrm{La}$ multitud ocupó especialmente los espacios desde la Plaza Mayor hasta la portada del Callao, donde aplaudió y exaltó a Bolívar, instituyendo un eco que se intensificó sucesivamente. ${ }^{71}$ La presencia de Bolívar había restablecido la vinculación entre la urbe y el puerto fragmentada por la guerra y, al mismo tiempo, la consonancia conmemorativa entre repiques de campanas y salvas de artillería. Pero más importante aún, se registró el eco de la multitud, especialmente cuando el Libertador se ubicó en el arco triunfal de la esquina de la calle Mercaderes, donde «se sintió una fuerte conmoción»:

De los dos órdenes de barandas que dominaban los portales, de las galerías de palacio, de las gradas de la Catedral y de la area de ese gran cuadro, repitió simultáneamente la muchedumbre, que en todos estos puntos aun estaba comprimida, un viva a BOLIVAR que semejo la voz omnipotente de la naturaleza, o la del cielo, que no puede comunicarse a la tierra sin estremecerla en sus cimientos. ${ }^{72}$

Esta descripción de un evento único sin precedentes en la cotidianeidad sonora del escenario urbano limeño mitificaba al héroe en el corazón del poder político y simbólico del gobierno. La vitalidad y voluminosidad de las vivas y el eco de Bolívar respondían al proceso de «sobrehumanización»e «hipersimbolización» del Libertador. ${ }^{73}$ La voz de la multitud al

${ }^{69}$ Sobre la paternidad sublime de Bolívar, véase Ortemberg 2014, específicamente la sección titulada «El ceremonial bolivariano: el padre del Perú y sus entradas triunfales». Las ideas sobre el eco y la resonancia las he extraído de Scott 1991 y Birdsall 2012: 28.

${ }^{70}$ Fundación Eugenio Mendoza 1967, III: 277.

${ }^{71}$ Ib.: 281-282.

$72 \mathrm{Ib}$.

${ }^{73}$ Salvador 2001: 40 . 
memorializar la imagen heroica del Libertador buscaba equiparse con los ruidos producidos por la naturaleza y estremecer la ciudad. Esta actitud guarda relación con lo señalado por Mark Smith, quien afirma que los ruidos de la guerra al ser tan estruendosos son comparados con los de la naturaleza. ${ }^{74}$ En efecto, la población limeña confundía los ruidos de los temblores con los sentidos a causa del conflicto bélico. ${ }^{75}$ Este énfasis en el poder estremecedor de la acción vocal colectiva cobraba mayor notoriedad para el caso limeño, ya que el natalicio de Bolívar se celebraba el 28 de octubre, día de gran recordación para la población limeña debido a la ocurrencia del devastador terremoto de $1746 .{ }^{76} \mathrm{Al}$ finalizar la guerra, con el silenciamiento de la sonoridad disruptiva de los cañones, el eco urbano celebrando a Bolívar se constituyó en el elemento sonoro hegemónico que marcó los escenarios centrales de la ciudad de Lima.

\section{A MODO DE CONCLUSIÓN}

Desde 1819, con el inicio del bloqueo de lord Cochrane al Callao, hasta 1826, cuando las fuerzas realistas capitularon en las fortalezas del Callao, la guerra por la independencia del Perú de España transformó el ambiente sonoro de la ciudad de Lima. Durante el periodo mencionado, la población limeña experimentó una amplia gama de sonidos que revelaron, por un lado, la intensidad sonora del conflicto bélico y, por otro, el esfuerzo por la implantación del régimen independiente. A nivel disruptivo, los bloqueos en el Callao y la evacuación e ingreso en diferentes oportunidades de los ejércitos realista o patriota produjeron conmociones sonoras a raíz del intenso cañoneo, el violento repique de las campanas, los silencios prolongados, entre otros. A nivel conmemorativo, desde la proclamación de la independencia en julio de 1821, el

\footnotetext{
${ }^{74}$ Smith 2001: 199.

75 Proctor 1971-1976. Resulta llamativo el ejemplo de García Camba cuando señala que «el 9 de julio por la noche, entraron 200 caballos enemigos, y atravesaron la ciudad en el momento que la población espantada sufrió un temblor de tierra de los más fuertes y de mayor duración que se han experimentado en aquel país donde son hartos frecuentes» (García Camba 1916, I: 538).

${ }^{76}$ Fundación Eugenio Mendoza 1967, III: 153-154.
} 
régimen independiente, con el objetivo de legitimar su proyecto político, reguló la sonoridad emanada por los repiques de las campanas, las salvas de artillería y los ecos festivos.

El estudio de la sonoridad conmemorativa y disruptiva en tiempos de la independencia hace posible lograr una aproximación a la dimensión sensorial de la guerra y, al mismo tiempo, evaluar la trasformación política y simbólica experimentada durante este periodo crucial de la historia de la ciudad de Lima. La sonoridad conmemorativa revela el esfuerzo del régimen independiente por construir una «comunidad imaginada de oyentes», pero, como cada uno de los tres momentos presentados, la dinámica de la guerra tuvo un peso determinante. La sonoridad disruptiva de las campanas proporciona indicios suficientes sobre la crisis urbana que significaron las evacuaciones de los ejércitos de la capital peruana. Las campanas jugaron un papel clave al emitir una especie de código sonoro, cuyo violento toque comunicó de manera estrepitosa la apropiación plebeya de las mismas en 1821 y la estratégica pérdida de la fortaleza del Callao en febrero de 1824. Asimismo, los repiques de las campanas al anunciar el ingreso de los ejércitos proporcionaron seguridad emocional, como ocurrió en julio de 1821 con la toma de la capital por el ejército patriota o el reingreso de este en julio de 1823. Esta actitud no es accidental. Ya para el caso mexicano se ha comprobado que durante la guerra de independencia las autoridades militares emplearon las campanas unidas a las salvas de cañón, incluso los comandantes militares empezaron a controlar los repiques de las campanas reemplazando a los párrocos. ${ }^{77}$

La sonoridad disruptiva de los cañones demuestra la íntima relación entre la urbe y el puerto. En especial destaca el protagonismo espacial de la fortaleza del Real Felipe. En 1819, como el testimonio del virrey Pezuela lo confirma, el estruendo sonoro del bloqueo al Callao llevado a cabo por la escuadra de lord Cochrane anunció que la ciudad de Lima se convertía en teatro de guerra. En 1826, salvas de artillería saludando el triunfo patriota sobre la resistencia realista comunicaban a la población el fin de la guerra. En el transcurso de estos años, la sonoridad disruptiva 
de la artillería fue de tal magnitud que superó ampliamente la sonoridad conmemorativa de las mismas. Más aun, debido a su potente presencia, influyeron en la regulación de la sonoridad conmemorativa, tal como lo expresa la cautela sonora castrense al ingreso del ejército patriota a la ciudad de Lima, la "amputación sonora» de la proclamación de la independencia en 1821 y el protagonismo de la acción vocal de la multitud exaltando al Libertador, el cual hemos identificado como el eco a Bolívar. Si el estruendo marcial de los cañones recibió a Bolívar en 1823 en un hecho sin precedentes, en 1825 y 1826 , debido a la cacofonía bélica sonora del bloqueo al Callao, la voz de la multitud cobró preeminencia.

\section{BIBLIOGRAFÍA}

Aljovín de Losada, Cristóbal. 2001. «La Constitución de 1823». En O’Phelan, Scarlett (comp.). La Independencia en el Perú. De Los Borbones a Bolivar. Lima: Instituto Riva-Agüero, 351-378.

Álvarez Jonte, Antonio. 1971-1976. «Diario general de los acontecimientos más notables de la escuadra nacional de Chile desde la noche del 14 de enero de 1819 en que zarpó de Valparaíso». En Denegri Luna, Félix (ed.). Colección Documental de la Independencia del Perú. Tomo XXVI: Memorias, diarios y crónicas. Lima: Comisión Nacional del Sesquicentenario de la Independencia del Perú, vol. 2: 431-459.

Anna, Timothy E. 2003. La caída del gobierno español en el Perú. El dilema de la independencia. Traducción de Gabriela Ramos. Lima: Instituto de Estudios Peruanos.

Archivo Nacional. 1946-1985. Archivo de don Bernardo O'Higgins. Santiago de Chile: Ed. Nascimento, Imprenta Universitaria, Universidad Católica y Editorial del Pacífico, 33 vols.

«Bando para la Proclamación de la Independencia». 1821. Gaceta del Gobierno de Lima Independiente. Núm. 5, 25 de julio: 17-18.

Barbón, María Soledad. 2012. "De la "muy noble y muy leal” a la "heroica y esforzada” ciudad de Lima: rituales públicos durante la transición a la Independencia». En Mc Evoy, Carmen; Mauricio Novoa y Elías José Palti (eds.). En el Nudo del Imperio: Independencia y Democracia en el Perú. Lima: Instituto de Estudios Peruanos e Instituto Francés de Estudios Andinos, 171-186. 
Barra, Felipe de la (ed.). 1971-1976. Colección Documental de la Independencia del Perú. Tomo VI: Asuntos Militares. Vol. 3: Juntas de Guerra (1820-1821). Lima: Comisión Nacional del Sesquicentenario de la Independencia del Perú.

Birdsall, Carolyn. 2012. Nazi Soundscapes: Sound, Technology and Urban Space in Germany, 1933-1945. Ámsterdam: Amsterdam University Press. Boutin, Aimée. 2015. City of noise: sound and nineteenth-century Paris. Urbana: University of Illinois Press.

Burgess, Clive y Andrew Wathey. 2000. «Mapping the Soundscape: Church Music in English Towns, 1450-1550». Early Music History. Núm. 19: 1-46. Disponible en: <http://dx.doi.org/10.1017/ s0261127900001959>.

Carbajal López, David. 2010. «Campanas, religión y buen gobierno en Orizaba». Secuencia. Revista de Historia y Ciencias Sociales. Núm. 77: 15-37. Disponible en: <http://dx.doi.org/10.18234/secuencia. v0i77.1114>.

Cochrane, Thomas. 1863. Memorias de lord Cochrane, Conde de Dundonald. Traducción de Manuel Bilbao. Lima: Imprenta de José Masías.

Comisión Nacional del Centenario. 1910-1911. «Parte del capitán Crosbie. Fragata O’Higgins, bahía del Callao, 25 de julio de 1821». En Documentos del Archivo San Martín. Buenos Aires: Imprenta de Coni Hermanos, t. XI.

Concha, Manuel Santiago. 1971-1976. «Los Patriotas de Lima en la noche feliz. Drama en dos actos compuesto por M. C.». En Ugarte Chamorro, Guillermo (ed.). Colección Documental de la Independencia del Perú. Tomo XXV: El Teatro en la Independencia. Lima: Comisión Nacional del Sesquicentenario de la Independencia del Perú, vol. 2: 7-49.

Corbacho, Jorge M. 1911. El 28 de Julio de 1821, según relaciones de testigos presenciales. Lima.

Corbin, Alain. 1998. Village Bells: Sound and Meaning in the 19th-century French Countryside. Traducción de Martin Thom. Nueva York: Columbia University Press.

Dávalos, Marcela. 2011. «El lenguaje de las campanas». Revista de Historia Social y de las Mentalidades. Vol. I, núm. 5: 181-198.

DeFazio, Kimberly. 2011. The city of the senses: urban culture and urban space. Nueva York: Palgrave Macmillan. 
Delano, Amasa. 1971-1976. «Impresiones de Lima Virreinal en 1805 y 1806». En Núńez, Estuardo (ed.). Colección Documental de la Independencia del Perú. Tomo XXVII: Relaciones de Viajeros. Lima: Comisión Nacional del Sesquicentenario de la Independencia del Perú, vol. 1: 1-37. Denegri Luna, Félix (ed.). 1971-1976a. Colección Documental de la Independencia del Perú. Tomo XIV: Obra Gubernativa y Epistolario de Bolivar. Lima: Comisión Nacional del Sesquicentenario de la Independencia del Perú, 4 vols.

. 1971-1976b. Colección Documental de la Independencia del Perú. Tomo XXVI: Memorias, diarios y crónicas. Lima: Comisión Nacional del Sesquicentenario de la Independencia del Perú, 4 vols.

«Don José Bernardo Tagle Presidente de la República del Perú». 1823. Gaceta del Gobierno extraordinaria. Núm. 7, 17 de agosto. Edición facsimilar. Caracas: Fundación Eugenio Mendoza, vol. I: 239.

Espejo, Gerónimo. 1971-1976. «Apuntes Históricos sobre la Expedición Libertadora del Perú en 1820 por el coronel Gerónimo Espejo». En Denegri Luna, Félix (ed.). Colección Documental de la Independencia del Perú. Tomo XXVI: Memorias, diarios y crónicas. Lima: Comisión Nacional del Sesquicentenario de la Independencia del Perú, vol. 2: 369-429.

Fundación Eugenio Mendoza. 1967. Gaceta del Gobierno del Perú. Edición facsimilar. Caracas: Fundación Eugenio Mendoza, 3 vols.

Gálvez Peña, Carlos. 2012. «El rey, la Constitución y la patria. Prédica y cultura política en el Perú durante la primera mitad del siglo XIX». En Mc Evoy, Carmen, Mauricio Novoa y Elías José Palti (eds.). En el Nudo del Imperio: Independencia y Democracia en el Perú. Lima: Instituto de Estudios Peruanos e Instituto Francés de Estudios Andinos, 151-170.

Gamio Palacio, Fernando. 1971. La municipalidad de Lima y la emancipación, 1821. Lima: Consejo Provincial de Lima, Comisión Municipal del Sesquicentenario de la Independencia Nacional.

García Camba, Andrés. 1916. Memorias del general García Camba para la historia de las armas españolas en el Perú, 1809-[1825]. Madrid: Editorial América, 2 vols.

Hall, Basil. 1971-1976. «El Perú en 1821»En Núñez, Estuardo (ed.). Colección Documental de la Independencia del Perú. Tomo XXVII: Relaciones de Viajeros. Lima: Comisión Nacional del Sesquicentenario de la Independencia del Perú, vol. 1: 199-268. 
Hébrard, Véronique. 2003a. «La ciudad y la guerra en la historiografía latinoamericana (siglo XIX)». Anuario Americanista Europeo. Núm. 1: 41-58. . 2003b. "Ciudades y guerra civil en la Independencia de Venezuela, 1812-1823». Tiempos de América. Revista de Historia, Cultura y Territorio. Núm. 10: 99-108.

2012. Venezuela Independiente: Una nación a través del discurso (1808-1830). Traducción de Amelia Hernández. Frankfurt y Madrid: Vervuert, Iberoamericana.

Herrera, José Hipólito. 1862. El álbum de Ayacucho. Colección de los principales documentos de la guerra de la independencia del Perú, y de los cantos de victoria y poesías relativas a ella. Lima: Tipografía de Aurelio Alfaro.

J. M. V. 1825. Oda: Lima libre y pacifica. Lima: J. Gonzalez. Disponible en: <http://babel.hathitrust.org/cgi/pt?id=yale.39002085763853;view $=1$ up;seq=8>.

Kutzler, Evan A. 2014. "Captive Audiences: Sound, Silence, and Listening in Civil War Prisons». Journal of Social History. Vol. XLVIII, núm. 2: 239-263. Disponible en: <http://dx.doi.org/10.1093/jsh/shu130>.

Mariátegui, Francisco Javier. 1971-1976. «Anotaciones a la historia del Perú independiente de don Mariano Felipe Paz Soldán, (1819-1922)». Denegri Luna, Félix (ed.). Colección Documental de la Independencia del Perú. Tomo XXVI: Memorias, diarios y crónicas. Lima: Comisión Nacional del Sesquicentenario de la Independencia del Perú, vol. 2: 1-157.

Montoya, Gustavo. 2002. La Independencia del Perú y el fantasma de la revolución. Lima: Instituto de Estudios Peruanos e Instituto Francés de Estudios Andinos.

Nava, María del Carmen e Isabel Fernández Tejedo. 2010. «El grito de Dolores y la campana de la Independencia. Reseña histórica del festejo patriótico y el simbolismo nacional». En Gálvez Medrano, Arturo y Felipe Gálvez Cancino (coords.). Pensar el futuro de México. Colección Conmemorativa de las Revoluciones Centenarias. Ciudad de México: Universidad Autónoma Metropolitana, 19-76.

Odriozola, Manuel. 1863-1877. Documentos históricos del Perú en las épocas del coloniaje después de la conquista y de la independencia hasta la presente. Lima: Tip. de A. Alfaro, 10 vols.

Ortemberg, Pablo. 2006. «Las primeras fiestas cívicas en el Perú independiente: emblemática y ceremonial bajo el Protectorado». Revista Andina. Núm. 43: 239-268. 
2009. «La entrada de José de San Martín en Lima y la proclamación del 28 de julio: la negociación simbólica de la transición». Histórica. Vol. XXXIII, núm. 2: 65-108

. 2012. "Independencia, rituales y poder en Lima. Entrevista a Pablo Ortemberg». Historia Global Online. Disponible en: <http:// historiaglobalonline.com/2012/12/30/independencia-rituales-y-poderen-lima-entrevista-a-pablo-ortemberg/>.

. 2014. Rituales del poder en Lima (1735-1828): de la monarquia a la república. Lima: Pontificia Universidad Católica del Perú.

Oviedo, Juan (ed.). 1861-1872. Colección de Leyes, decretos y órdenes publicadas en el Perú desde el año de 1821 hasta 31 de diciembre de 1859: reimpresa por orden de materias. Lima: Felipe Bailly, 16 vols.

Paroissien, James. 1971-1976. «Anotaciones para un Diario (agosto 18 de 1820-marzo 19 de 1821)». En Denegri Luna, Félix (ed.). Colección Documental de la Independencia del Perú. Tomo XXVI: Memorias, diarios y crónicas. Lima: Comisión Nacional del Sesquicentenario de la Independencia del Perú, vol. 2: 534-599.

Pezuela, Joaquín de la. 1947. Memoria de gobierno. Edición y prólogo de Vicente Rodríguez Casado y Guillermo Lohmann Villena. Sevilla: Escuela de Estudios Hispano-Americanos de la Universidad de Sevilla. Pinch, Trevor y Karin Bijsterveld. 2013. «New Keys to the World Sound». En Pinch, Trevor y Karin Bijsterveld (eds.). The Oxford Handbook of Sound Studies. Nueva York: Oxford University Press. Disponible en: <http://dx.doi.org/10.1093/oxfordhb/9780195388947.013.0010>.

Proctor, Robert. 1971-1976. «El Perú entre 1823 y 1824». En Núñez, Estuardo (ed.). Colección Documental de la Independencia del Perú. Tomo XXVII: Relaciones de Viajeros. Lima: Comisión Nacional del Sesquicentenario de la Independencia del Perú, vol. 2: 187-338.

Reales exequias, que por el fallecimiento del señor don Carlos III., Rey de España $y$ de Las Indias, mando celebrar en la ciudad de Lima: capital del Perú, el excelentísimo señor don Teodoro de Croix, caballero de Croix. 1789. Lima: Imprenta Real de los Niños Expósitos.

Salvador, José María. 2001. Efímeras efemérides: fiestas cívicas y arte efímero en la Venezuela de los siglos XVII-XIX. Caracas: Universidad Católica Andrés Bello. 
Scott, Joan W. 1991. «The Evidence of Experience». Critical Inquiry. Vol. XVII, núm. 4: 773-797.

Smith, Bruce R. 1999. The acoustic world of early modern England: attending to the O-factor. Chicago: University of Chicago Press. 1999

Smith, Mark M. 2001. Listening to Nineteenth-Century America. Chapel Hill: University of North Carolina Press.

.2014. The smell of battle, the taste of siege: a sensory history of the Civil War. Nueva York: Oxford University Press.

Stevenson, William Bennet. 1971-1976. «Memorias sobre las campañas de San Martín y Cochrane en el Perú». En Núñez, Estuardo (ed.). Colección Documental de la Independencia del Perú. Tomo XXVII: Relaciones de Viajeros. Lima: Comisión Nacional del Sesquicentenario de la Independencia del Perú, vol. 3: 73-338.

Terralla y Landa, Estevan. 1790. El sol en el medio día: año feliz, jubilo particular con que la nacion indica de esta muy noble ciudad de Lima solemnisó la exaltacion al trono de Ntro. augustísimo monarca el señor don Carlos IV. Lima: Casa Real de Niños Expósitos, 1790.

Thomson, James. «Impresiones de Lima entre 1822 y 1824». 1971-1976. En Núñez, Estuardo (ed.). Colección Documental de la Independencia del Perú. Tomo XXVII: Relaciones de Viajeros. Lima: Comisión Nacional del Sesquicentenario de la Independencia del Perú, vol. 2: 1-82.

Torrente, Mariano. 1829-1830. Historia la Revolución Hispano-americana. Madrid: Imprenta de Moreno, 3 vols.

1971-1976. «Historia de la Revolución de la Independencia del Perú». En Denegri Luna, Félix (ed.). Colección Documental de la Independencia del Perú. Tomo XXVI: Memorias, diarios y crónicas. Lima: Comisión Nacional del Sesquicentenario de la Independencia del Perú, vol. 4. Valenzuela Márquez, Jaime. 2001. Las liturgias del poder: Celebraciones públicas y estrategias persuasivas en Chile colonial (1609-1709). Santiago de Chile: Dirección de Bibliotecas, Archivos y Museos.

2010a. «Entre campanas y cañones: Perspectivas sobre la sonoridad política en el Santiago Borbónico». Revista de Historia Iberoamericana. Vol. III, núm. 1: 69-83. . 2010b. Fiesta, Rito y Politica. Del Chile borbónico al republicano. Santiago de Chile: Dirección de Bibliotecas, Archivos y Museos. 
Wolmar, Alex. 2014. «In storms of steel. The soundscape of World War I and its impact on auditory media culture during the Weimar Period». En Morat, Daniel (ed.). Sounds of modern history: auditory cultures in 19th-and 20th-century Europe. Nueva York: Berghahn Books, 227-255.

Fecha de recepción: 24/VIII/2015

Fecha de aceptación: 27/III/2016 